\title{
KINETIC MODEL FOR DISSOLUTION OF CEMENT COPPER IN SULFURIC ACID SOLUTIONS CONTAINING CUPRIC IONS
}

\author{
Nizamettin Demirkıran ${ }^{1,}$, G. Deniz Turhan $\ddot{O}_{z d e m i r}{ }^{1}$
}

https://doi.org/10.23939/chcht15.03.395

\begin{abstract}
In this paper, the dissolution kinetics of cement copper powder in sulfuric acid solutions containing cupric ions was examined. It was observed that the dissolution rate of copper increased with increasing the acid concentration, temperature, and stirring speed. It was determined that the dissolution rate of copper enhanced with increasing the cupric ion concentration up to $0.025 \mathrm{M}$. It was found that the temperature and concentration of cupric ion had more considerable effects on the dissolution of copper powder. The kinetic analysis of the process was performed, and it was observed that it fits the first order pseudo-homogenous reaction model. The activation energy was calculated to be $31.1 \mathrm{~kJ} / \mathrm{mol}$.
\end{abstract}

Keywords: malachite, cement copper, cupric ion, dissolution, kinetics.

\section{Introduction}

Various techniques, such as crystallization, ionic precipitation, reduction with a gas, solvent extraction, cementation, and electrolytic reduction can be utilized to recover the copper from the leach solution with or without practicing a purification method. Among these techniques, cementation method is a favorable route to gain copper from the purified or unpurified leach solution especially in small and medium-size hydrometallurgical plants because of its simplicity, ease of control, and low energy consumption. Cementation or metal displacement process based on electrochemical fundamental can be described as reduction of metal ions by galvanic interaction between noble metal ions and a more active metal in an aqueous solution medium without an external source of electrical current [1-4].

Copper powder recovered by a cementation method is mostly of poor quality because of the contaminations in the leach solution obtained and its disposition to oxidize during the dewatering stage $[5,6]$.

\footnotetext{
Department of Chemical Engineering, Faculty of Engineering, Inonu University, Malatya, 44280, Turkey

\nizamettin.demirkiran@inonu.edu.tr

(C) Demirkıran N., Turhan Özdemir G.D., 2021
}

However, copper powder obtained by this method can be refined by applying various methods, such as pyrometallurgical refining, electro-refining and hydrometallurgical treatment, and it can be used to be a commercial product in various areas. For the hydrometallurgical treatment of the low-grade cement copper, it must be dissolved in an aqueous solution $[6,7]$. Sulfuric acid is utilized as a leaching agent in most of the hydrometallurgical processes due to its good solving ability and cheapness. When the low-grade copper powder obtained by a cementation route is dissolved in an aqueous sulfuric acid solution, a solution containing copper ions is obtained, and this solution can be used to produce the high-purity electrolytic copper. Besides, some copper compounds can be also manufactured from the solution containing copper ions by means of precipitation, evaporation and crystallization [7-10].

In the previous study, the dissolution of copper powder recovered by the cementation method from the actual leach solution obtained after the leaching of malachite ore was investigated in hydrochloric acid solutions [11]. But, a kinetic analysis was not made in the mentioned work. The aims of the present study were to examine the dissolution kinetics of cement copper produced by metal displacement reaction from the actual leach solutions obtained after the dissolution of malachite ore in ammonium sulfate solutions and to determine the effects of the experimental parameters including acid concentration, cupric ion concentration, stirring speed and temperature, on the dissolution rate.

\section{Experimental}

The study was carried out at three stages including the leaching of malachite, cementation of copper, and dissolution of cement copper. The cement copper was produced using the actual leach solution obtained after the leaching of malachite ore in ammonium sulfate solutions. An XRD analysis result of malachite sample is given in Fig. 1. As can be seen from Fig. 1, the ore sample used in this study includes mainly malachite $\left(\mathrm{CuCO}_{3} \mathrm{Cu}(\mathrm{OH})_{2}\right)$, smithsonite $\left(\mathrm{ZnCO}_{3}\right)$, and quartz $\left(\mathrm{SiO}_{2}\right)$. 


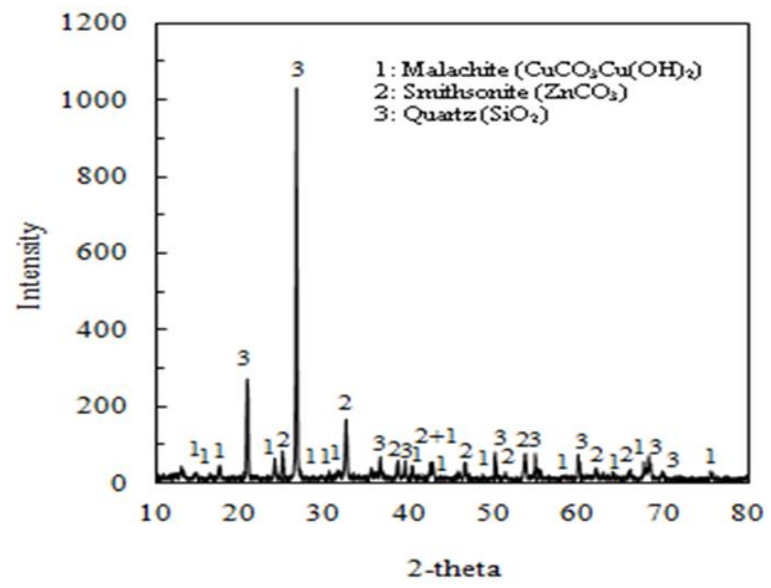

Fig. 1. XRD diffraction pattern of malachite ore used in the study

The chemical analysis of ore showed that it contained $50.41 \% \mathrm{SiO}_{2}, 15.23 \% \mathrm{ZnO}, 10.55 \% \mathrm{CuO}, 8.43 \% \mathrm{Fe}_{2} \mathrm{O}_{3}$, $1.81 \% \mathrm{Al}_{2} \mathrm{O}_{3}, 1.17 \%$ other oxides. The loss ignition of the ore was determined to be $12.40 \%$ at $1073 \mathrm{~K}$.

Before recovering of metallic copper by a cementation method, the leaching experiments were performed to obtain the actual leach solution containing copper ions. Because the leaching kinetics of malachite ore in the ammonium sulfate solution was investigated in our previous study [9], the effects of the experimental parameters on the leaching process were not indicated here. In the present study, the mother leach solution was prepared as follows. After adding 11 of an ammonium sulfate solution with a concentration of $4 \mathrm{M}$ into the glass reactor and heating to the reaction temperature of $323 \mathrm{~K}$, $15 \mathrm{~g}$ of malachite ore sample having average particle size of $62.4 \mu \mathrm{m}$ was added to the solution, and the stirring speed was set as $500 \mathrm{rpm}$. The leaching process was carried out for $240 \mathrm{~min}$ reaction time. After the leaching process, the undissolved part of ore and solution was separated by filtration, and the mother leach solution was

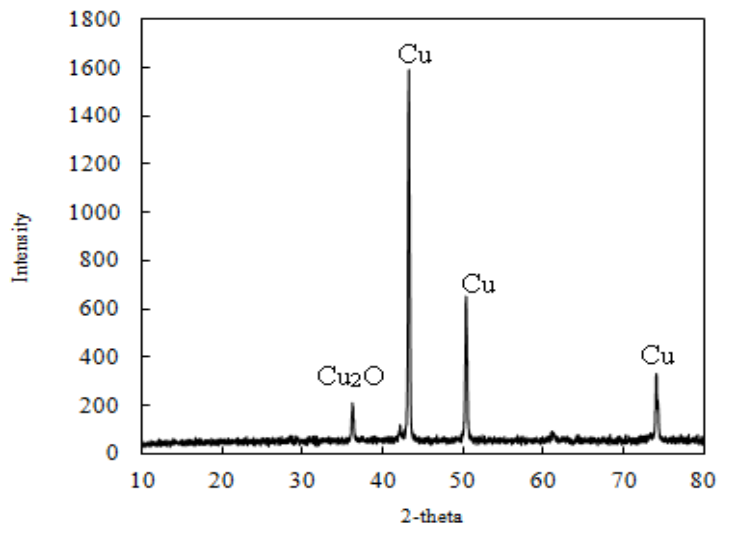

Fig. 2. XRD pattern of copper powder produced by cementation obtained. When it was necessary, the mother solution containing copper ions was prepared according to the same procedure. The amount of dissolved copper was calculated complexometrically using Titriplex III solution as titrant and murexide as an indicator. It was determined that the leaching extent of ore was to be approximately $94 \%$. The copper concentration in the mother solution obtained after filtration was calculated to be $1.15 \mathrm{~g} / \mathrm{l}$.

After the actual leach solution was obtained, this solution was used to produce copper powder by a cementation process. The experimental setup was identical with the dissolution process. After placing $500 \mathrm{ml}$ of the stock solution containing $1.15 \mathrm{~g} / 1$ of copper ions into the glass reactor and heating to $313 \mathrm{~K}, 1.5$ times of stoichiometrically required zinc granules $(5 \pm 0.5 \mathrm{~mm}$ diameter) were added to the reactor to precipitate copper ions in the solution, and the reactor content was stirred at $500 \mathrm{rpm}$ for 75 min cementation time. $\mathrm{pH}$ of the solution was adjusted to 3 at the beginning of the experiment. At the end of the cementation reaction, the amount of the remained copper ions in the solution was calculated by the complexometric method as in the leaching step. It was determined that almost all of copper in the mother solution was precipitated by the zinc cementation. The solid precipitate composed of metallic copper was separated by filtration from the aqueous phase, washed with distilled water, and then dried at $323 \mathrm{~K}$ in air. Thus, the cement copper powder was manufactured. This powder was treated with diluted sulfuric acid solution to remove the impurities arising from the leach solution and drying process. An XRD pattern of the red-brown copper powder obtained after acid cleaning treatment is given in Fig. 2.

The major diffraction peaks in Fig. 2 correspond to the metallic copper while the minor peaks indicate the cuprous oxide phase. The copper content of the cleaned powder was determined to be $96 \%$. A SEM image of copper powder is shown in Fig. 3. This figure shows that the cubic cuprous oxide is formed on the surface of copper powder.

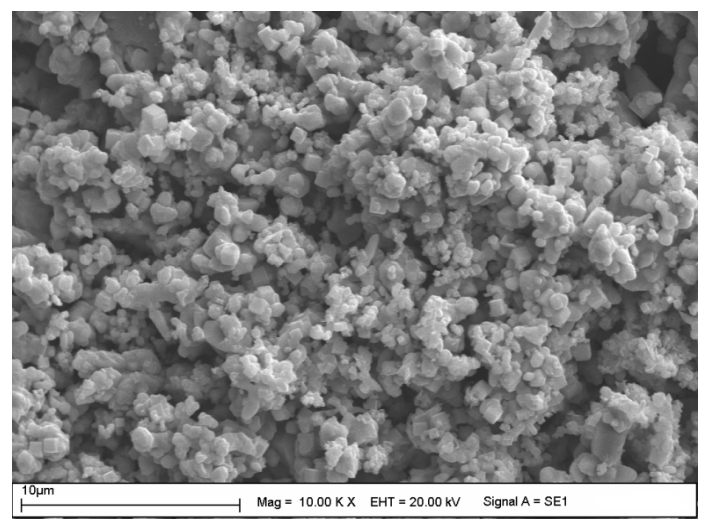

Fig. 3. SEM image of copper powder produced by cementation 
In the experiments of cement copper dissolution, the experimental setup was identical with the leaching and cementation processes. After $300 \mathrm{ml}$ of sulfuric acid solution containing cupric ions was poured into a glass reactor and heated to the desired reaction temperature, a given amount of cement copper was added to the acid solution. The reactor content was mixed by a mechanic stirrer at the predetermined stirring speed. Sulfuric acid solutions containing cupric ions were prepared by dissolving the necessary amount of $\mathrm{CuSO}_{4} \cdot 5 \mathrm{H}_{2} \mathrm{O}$ in the sulfuric acid solution. During dissolution experiments of copper powder, oxygen used as an oxidizing agent was supplied from air. Air was provided by using an aquar- ium pump. Aliquots of $2 \mathrm{ml}$ each were withdrawn at regular intervals during the dissolution process to monitor the progress of reaction, and the dissolved copper content was determined by a complexometric titration. The dissolved percentage of cement copper was calculated as follows:

$$
\% \text { dissolved copper }=\frac{\text { amount of dissolved copper }}{\text { amount of copper in cemented product }} \cdot 100
$$

In the dissolution experiments, the effects of concentration of sulfuric acid, concentration of cupric ion, temperature, and stirring speed on the dissolution of cement copper were examined. The experimental parameters and their values are given in Table 1 .

Table 1

The parameters and their values used in the dissolution experiments of cement copper

\begin{tabular}{|l|l|}
\hline \multicolumn{1}{|c|}{ Parameter } & \multicolumn{1}{|c|}{ Value } \\
\hline Acid concentration, $\mathrm{M}$ & $0.25,0.5,1,2$ \\
\hline $\mathrm{Cu}(\mathrm{II})$ concentration, $\mathrm{M}$ & $0.005,0.01,0.025,0.05,0.075,0.1$ \\
\hline Temperature, $\mathrm{K}$ & $323,333,343,353,363$ \\
\hline Stirring speed, rpm & $300,400,500,600$ \\
\hline
\end{tabular}

\section{Results and Discussion}

The chemical reactions that occur during the leaching of malachite ore, cementation of copper, and dissolution of cement copper are shown below. During the leaching step, the overall reaction occurring between malachite and ammonium sulfate can be written as in Eq. (2).

$$
\begin{aligned}
\mathrm{CuCO}_{3} \cdot \mathrm{Cu}(\mathrm{OH})_{2}+2\left(\mathrm{NH}_{4}\right)_{2} \mathrm{SO}_{4} \rightarrow \\
\rightarrow 2 \mathrm{Cu}^{2+}+4 \mathrm{NH}_{3}+2 \mathrm{SO}_{4}{ }^{2-}+\mathrm{CO}_{2}+3 \mathrm{H}_{2} \mathrm{O}
\end{aligned}
$$

Copper ions passing into the solution generate copper amine complexes with ammonia according to the reactions in Eqs. (3) and (4).

$$
\begin{gathered}
\mathrm{Cu}^{2+}+2 \mathrm{NH}_{3} \leftrightarrow \mathrm{Cu}\left(\mathrm{NH}_{3}\right)_{2}{ }^{2+} \\
\mathrm{Cu}\left(\mathrm{NH}_{3}\right)_{2}{ }^{2+}+2 \mathrm{NH}_{3} \leftrightarrow \mathrm{Cu}\left(\mathrm{NH}_{3}\right)_{4}{ }^{2+}
\end{gathered}
$$

At the cementation stage, the metal displacement reaction between copper ions and metallic zinc occurs according to Eq. (5) due to the difference between the standard electrode potentials of two metals.

$$
\mathrm{Cu}^{2+}+\mathrm{Zn}^{\circ} \rightarrow \mathrm{Cu}^{\circ}+\mathrm{Zn}^{2+}
$$

The reaction mechanism for the dissolution of copper in the aerated sulfuric acid solution has been proposed in the literature [12-19]. The dissolution of cement copper in aerated sulfuric acid solutions occurs according to the reaction in Eq. (6). In this reaction, metallic copper reacts essentially with hydrogen released from sulfuric acid and oxygen dissolved in the molecular state in the solution. Oxygen acts as an oxidizing agent and facilitates the copper dissolution.

$$
\mathrm{Cu}^{0}+2 \mathrm{H}^{+}+1 / 2 \mathrm{O}_{2} \rightarrow \mathrm{Cu}^{2+}+\mathrm{H}_{2} \mathrm{O}
$$

Cupric ions generated by Eq. (6) can also act as an oxidizing agent [20], and it can oxidize the cement copper to cuprous ions as shown in Eq. (7).

$$
\mathrm{Cu}^{2+}+\mathrm{Cu} \rightarrow 2 \mathrm{Cu}^{+}
$$

Cuprous ion is not stable in aqueous solutions, and it can be oxidized to a cupric ion in oxygenated acidic solutions according to Eq. (8).

$$
2 \mathrm{Cu}^{+}+2 \mathrm{H}^{+}+1 / 2 \mathrm{O}_{2} \rightarrow 2 \mathrm{Cu}^{2+}+\mathrm{H}_{2} \mathrm{O}
$$

Finally, the net reaction for the dissolution of cement copper in the oxygenated sulfuric acid solutions can be written as in Eq. (9).

$$
\mathrm{Cu}^{0}+2 \mathrm{H}_{2} \mathrm{SO}_{4}+1 / 2 \mathrm{O}_{2} \rightarrow \mathrm{Cu}^{2+}+2 \mathrm{SO}_{4}{ }^{2-}+2 \mathrm{H}_{2} \mathrm{O}
$$

The effect of sulfuric acid concentration on the dissolution of the copper powder in the absence of cupric ions was researched in the range of $0.25-2.0 \mathrm{M}$ for different reaction times. In these experiments, the reaction temperature, amount of copper, and stirring speed were taken to be $353 \mathrm{~K}, 0.25 \mathrm{~g}$, and $500 \mathrm{rpm}$, respectively. The results relating to these tests are shown in Fig. 4.

It can be seen from Fig. 4 that the dissolution rate of cement copper powder increases with increasing the sulfuric acid concentration. The percentage of copper dissolution increased from 66.3 to $81.5 \%$ after $180 \mathrm{~min}$ of reaction time when the acid concentration increased from 0.25 to $2.0 \mathrm{M}$.

To see whether or not cupric ions have an effect on the dissolution of cement copper, some tests were carried out in the sulfuric acid solutions at constant concentration of $1 \mathrm{M}$ containing cupric ions at different concentrations. The reaction temperature, amount of copper powder, and stirring speed were kept constant at $353 \mathrm{~K}, 0.25 \mathrm{~g}$, and $500 \mathrm{rpm}$, respectively, in these tests. Fig. 5 shows the effect of cupric ions on the dissolution of copper powder. Fig. 5 indicates that cupric ions have an important effect on the dissolution of cement copper. 


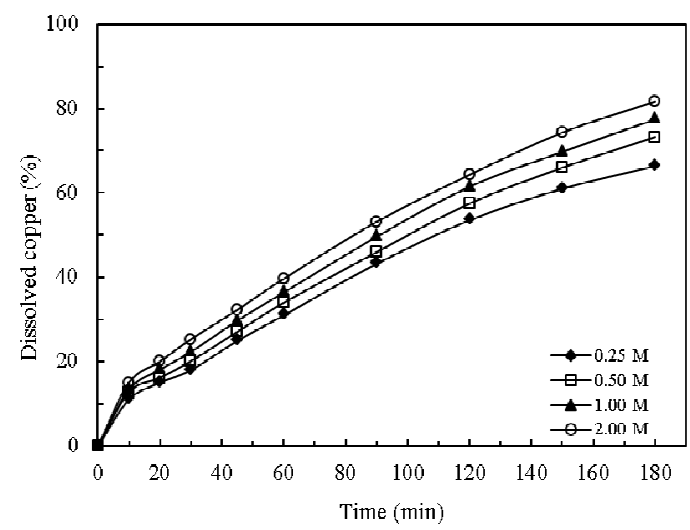

Fig. 4. Effect of sulfuric acid concentration on the dissolution of cement copper in the absence of cupric ions

The solutions used in these experiments contain cupric ions as an oxidizing agent along with oxygen. Addition of cupric ions into the oxygenated sulfuric acid solutions enhanced the dissolution rate of cement copper up to cupric ion concentration of $0.025 \mathrm{M}$. After this concentration value of cupric ions, the dissolution of copper powder decreased somewhat with increasing the cupric ion concentration. When there are no cupric ions in $1 \mathrm{M}$ sulfuric acid solution at the beginning of the experiment, the percentage of copper dissolution was determined to be $77 \%$ after $180 \mathrm{~min}$ of reaction time. When cupric ions at concentrations of $0.005,0.01,0.025$, $0.05,0.075$ and $0.1 \mathrm{M}$ were added into the sulfuric acid solution of $1 \mathrm{M}$, the percentages of the dissolution of cement copper were found to be $82.05,86.62$, 97.97, $94.90,92.21$ and $91.80 \%$, respectively, after $180 \mathrm{~min}$ of reaction time. Although there is a diminish in the dissolution of copper powder after the cupric ion concentration of $0.025 \mathrm{M}$, the dissolution values of cement powder in all solutions containing cupric ions are still higher than those in the solutions without cupric ions. Decrement of the dissolution rate of cement copper in the presence of cupric ions at concentrations higher than $0.025 \mathrm{M}$ can be attributed to the formation of $\mathrm{Cu}_{2} \mathrm{O}$ (cuprous oxide) and $\mathrm{CuO}$ (cupric oxide) films on the copper surface $[13,21]$. These oxide species can cause the passivation of copper and the dissolution rate of copper powder can diminish due to these oxides. In sulfuric acid solutions, cuprous oxide is insoluble or dissolves partly whereas cupric oxide has the high solubility. The formation rate of cuprous ions in the presence of cupric ions in the aerated sulfuric acid solution can increase according to the reaction in Eq. (7), and consequently more cupric ions are formed with regard to the reaction in Eq. (8). In conclusion, the dissolution rate of copper powder in a sulfuric acid solution containing cupric ion can increase. However, since more cuprous ion will arise

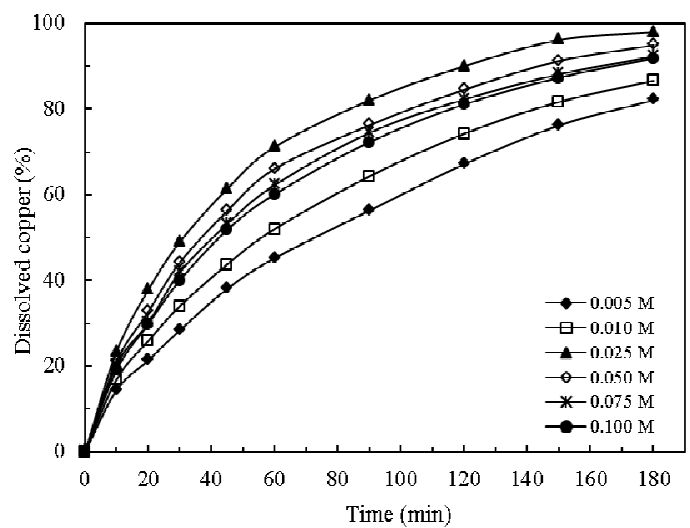

Fig. 5. Effect of cupric ion concentration on the dissolution of cement copper at constant sulfuric acid concentration

in the presence of cupric ions at high concentrations, the formation of passive cuprous oxide film on the metal surface may be excessive. In the literature, it has been said that this passive film is porous and adheres weakly to the metal surface when a cupric ion content in the solution is low. On the other hand, it has been reported that the cuprous oxide film becomes denser and adheres stronger to the copper surface as the cupric ion content in the solution increases $[13,14]$. In this case, the passive cuprous oxide film can inhibit the diffusion of cupric ions towards copper surface. Consequently, the dissolution rate of cement copper may decrease somewhat due to slowing the reactions in Eqs. (7) and (8). To reach the high dissolution values of cement copper in the aerated sulfuric acid solutions, the further dissolution experiments were performed by using the solutions containing cupric ions at constant concentration of $0.025 \mathrm{M}$. The results obtained for these experiments are given below.

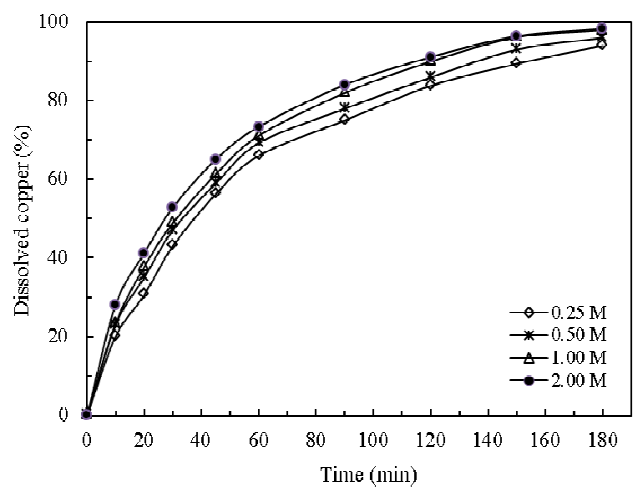

Fig. 6. Effect of sulfuric acid concentration on the dissolution of cement copper at the constant cupric ion concentration

To determine the effect of sulfuric acid concentration on the dissolution rate of copper powder in 
the presence of cupric ions, some experiments were conducted in the range of $0.25-2.0 \mathrm{M}$ for different reaction times. In these experiments, the reaction temperature, amount of copper powder, cupric ion concentration, and stirring speed were taken to be $353 \mathrm{~K}$, $0.25 \mathrm{~g}, 0.025 \mathrm{M}$, and $500 \mathrm{rpm}$, respectively. The results obtained from these experiments are given in Fig. 6. It can be seen from Fig. 6 that the dissolution rate of copper powder increases with increasing the sulfuric acid concentration in the presence of cupric ions at a constant concentration. When the results of Figs. 4 and 6 are compared, the effect of cupric ions on the dissolution of copper powder can be seen more obviously.

The dissolution percentages of cement copper in sulfuric acid solutions containing and not containing cupric ions for $180 \mathrm{~min}$ of reaction time are shown in Table 2. It can be seen from Table 2 that the cupric ions have an important effect on the dissolution rate of cement copper.

Table 2

Dissolution of cement copper in sulfuric acid solutions containing and not containing cupric ions

\begin{tabular}{|c|c|c|}
\hline \multirow{2}{*}{\begin{tabular}{c} 
Concentration of sulfuric acid, $M$ \\
\cline { 2 - 3 }
\end{tabular}} & $\begin{array}{c}\text { In sulfuric acid solutions not containing } \\
\text { cupric ions }\end{array}$ & $\begin{array}{c}\text { In sulfuric acid solutions containing cupric } \\
\text { ions of 0.025 M }\end{array}$ \\
\hline 0.25 & 66.37 & 94.50 \\
\hline 0.5 & 73.27 & 96.08 \\
\hline 1.0 & 77.45 & 97.97 \\
\hline 2.0 & 81.70 & 98.38 \\
\hline
\end{tabular}

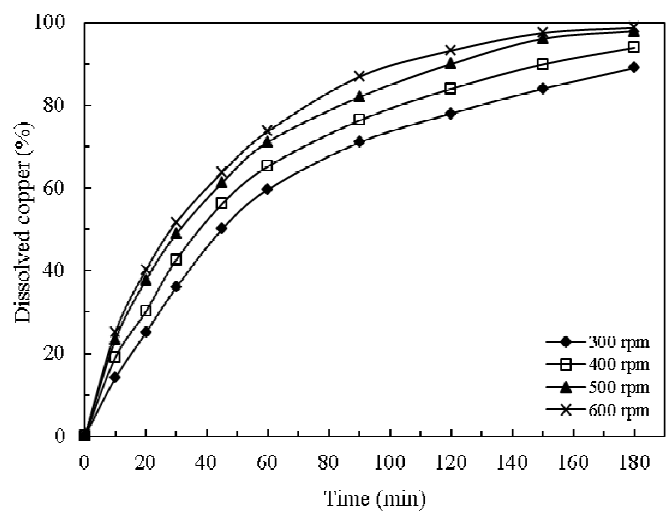

Fig. 7. Effect of stirring speed on the dissolution of cement copper in the presence of cupric ions

The effect of the stirring speed on the dissolution rate of copper powder was examined at the stirring speeds of 300, 400, 500 and $600 \mathrm{rpm}$. During these experiments, the acid concentration, reaction temperature, cupric ion concentration, and amount of cement copper were kept constant as $1 \mathrm{M}, 353 \mathrm{~K}, 0.025 \mathrm{M}$, and $0.25 \mathrm{~g}$, respectively. The results of the stirring speed tests are given in Fig. 7. It can be concluded from this figure that the stirring speed has an effect on the dissolution rate of copper powder. The diffusion through the boundary layer of liquid reagent towards the external surface of copper particles can be facilitated by means of the agitation of solution. Thus, the dissolution rate can increase with an increase in the stirring speed.

The effect of the reaction temperature on the dissolution rate of cement copper was investigated in a temperature range of $323-363 \mathrm{~K}$. In these experiments, the acid concentration, amount of cement copper, cupric ion concentration, and agitation speed were kept constant

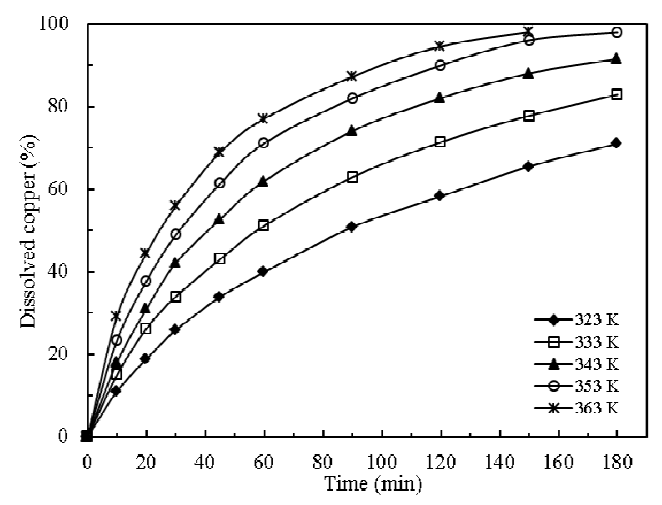

Fig. 8. Effect of reaction temperature on the dissolution of cement copper in the presence of cupric ions

as $1 \mathrm{M}, 0.25 \mathrm{~g}, 0.025 \mathrm{M}$, and $500 \mathrm{rpm}$, respectively. The variations of the dissolution rate of copper powder for various reaction temperatures are given in Fig. 8 .

Fig. 8 indicates that the temperature has a major effect on the dissolution of cement copper. At the temperature of $323 \mathrm{~K}, 71.03 \%$ of copper was dissolved after $180 \mathrm{~min}$ of reaction time, whereas at the temperature of $363 \mathrm{~K}, 98.07 \%$ of copper was dissolved only after $150 \mathrm{~min}$ of reaction time. Cuprous oxide film formed on the copper surface can become a denser and porous layer with an increase in the reaction temperature. Thus, the passive oxide layer can fluff, and its adhesion to copper surface can reduce. Consequently the dissolution rate of copper powder increases with increasing the reaction temperature.

The dissolution reaction between cement copper and acid solution is a heterogeneous reaction involving the mass transfer of reactants and products between the solid and fluid phases. The reactants transfer from the solution to the metal 
surface while the reaction product transfers from the surface into the bulk solution. The non-catalytic heterogeneous reaction models are commonly used to analyze the kinetics of fluid-solid reaction systems. The reaction between the solid and liquid reactants occurs on the outer surface of solid particle according to the shrinking core model, which is the most recognized model for the kinetic analysis of a noncatalytic heterogeneous reaction. According to the shrinking core model, the rate of a dissolution reaction between a solid material and solution may be controlled by one or more of the following steps: the diffusion through a fluid film, the diffusion through the product layer, or the chemical reaction on the surface of the unreacted core [22-24]. To determine the kinetic parameters and the rate-controlling step of dissolution process, the experimental data obtained were analyzed by using the mentioned models. If the dissolution process follows one of these models, then the straight lines passing through the origin should be obtained. When the models of the diffusion through a fluid film, the diffusion through a product layer, and the chemical reaction were applied to the experimental data obtained, it was observed that the parabolic curves were formed. Hence, it can be said that the heterogeneous reaction models are inappropriate to

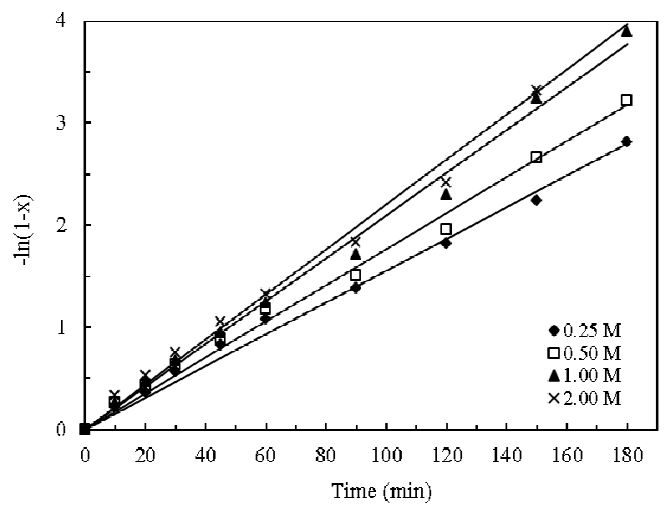

Fig. 9. Plot of $-\ln (1-x) v$ s. $t$ for different sulfuric acid concentrations at constant cupric ion concentration

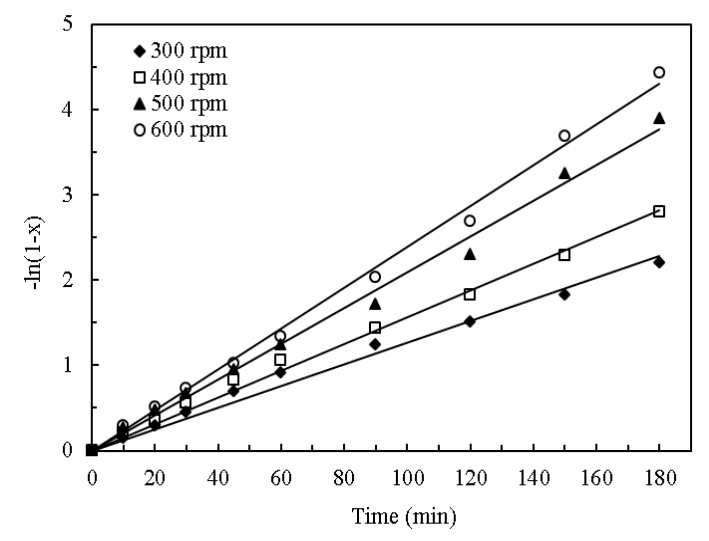

Fig. 11. Plot of $-\ln (1-x)$ vs. $t$ for different stirring speeds in the presence of cupric ions express the dissolution kinetics of cement copper in the sulfuric acid solutions containing cupric ions.

In addition to the non-catalytic heterogeneous reaction models, the homogeneous models are also applied to the experimental findings to derive the rate equation of heterogeneous reactions. Thus, the pseudohomogeneous models were applied to obtain the rate equation for this process. When the pseudo-homogeneous kinetic models were used, it was seen that the model in Eq. (10) could be more appropriate to describe the kinetics of the dissolution of cement copper.

$$
-\ln (1-x)=k \cdot t
$$

where $k$ is $\mathrm{n}$ apparent rate constant and $t$ is a reaction time, min.

If the dissolution process follows the model in Eq. (10), the plot of the left side of this equation versus time must be a straight line. Thus, the graphs of the left side of Eq. (10) versus reaction time were plotted for each reaction parameter. The graphs of $-\ln (1-x) v s$. $t$ for the concentration of sulfuric acid, concentration of cupric ions, stirring speed, and reaction temperature are given in Figs. 9-12, respectively.

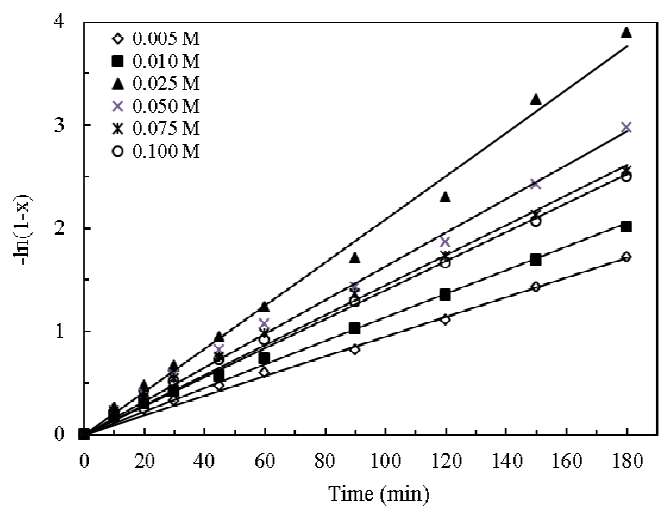

Fig. 10. Plot of $-\ln (1-x) v s$. $t$ for different cupric ion concentrations at constant sulfuric acid concentration

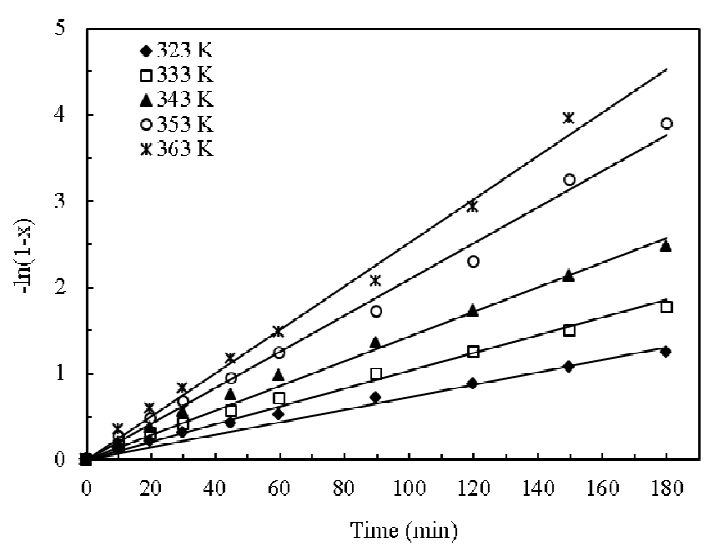

Fig. 12. Plot of $-\ln (1-x)$ vs. $t$ for different temperatures in the presence of cupric ions 
A semi-empirical model can be written as in Eq. (11) to include the effects of the reaction parameters on the rate constant of reaction.

$$
k=k_{0}\left(C_{A}\right)^{a} \cdot\left(C_{c u}\right)^{b} \cdot(S S)^{c} \exp \left(\frac{-E_{a}}{R T}\right)
$$

where $k_{0}$ is the frequency or pre-exponential factor, $1 / \mathrm{s} ; C_{A}$ is the concentration of sulfuric acid, $\mathrm{M} ; C_{C u}$ is the concentration of cupric ion, $\mathrm{M} ; S S$ is the stirring speed, $\mathrm{rpm} ; E_{a}$ is the activation energy, $\mathrm{J} / \mathrm{mol} ; R$ is the universal gas constant, $\mathrm{J} / \mathrm{mol} \cdot \mathrm{K}$, and $T$ is the reaction temperature, $\mathrm{K}$.

The constants $a, b$, and $c$ represent the dependence of the reaction rate on the relevant parameter. Combining Eqs. (10) and (11), the Eq. (12) is obtained:

$$
-\ln (1-x)=k_{0}\left(C_{A}\right)^{a} \cdot\left(C_{c u}\right)^{b} \cdot(S S)^{c} \exp \left(\frac{-E_{a}}{R T}\right) \cdot t
$$

The values of $a, b$, and $c$ can be calculated by using the apparent rate constants obtained from the slopes of the straight lines in Figs. 9-12. To estimate these constants, the plots of $\ln (k)$ versus $\ln \left(C_{A}\right), \ln (k)$ versus $\ln \left(C_{C u}\right)$, and $\ln (k)$ versus $\ln (S S)$ were constructed. For the concentration of cupric ion, a plot of $\ln (k)$ versus $\ln \left(C_{C u}\right)$ is shown in Fig. 13. As can be seen from Fig. 13, two straight lines were obtained.

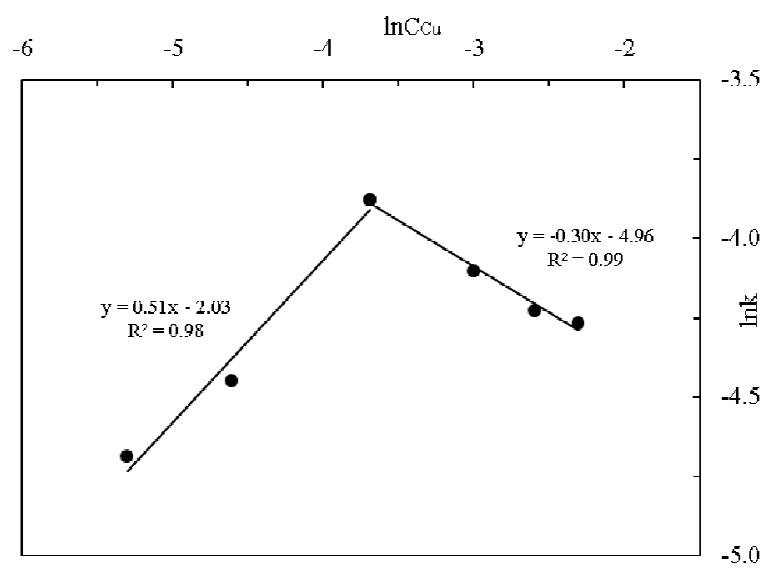

Fig. 13. Plot of $\ln \left(C_{C u}\right)$ versus $\ln (k)$

It could be seen from Figs. 5 and 10 that the dissolution rate of cement copper increased with increasing the cupric ion concentration up to $0.025 \mathrm{M}$. After the concentration of $0.025 \mathrm{M}$, further increase in the concentration of cupric ion led to a decrease in the dissolution rate of cement copper. For this reason, Eq. (12) does not apply to all concentrations of cupric ion. Thus, it would be more appropriate to write Eq. (12) as below. Eq. (12a) represents the effects of parameters on the dissolution kinetics up to the cupric ion concentration of $0.025 \mathrm{M}$, while Eq. (12b) shows the kinetic expression after this cupric ion concentration.

$$
\begin{aligned}
& -\ln (1-x)=k_{0}\left(C_{A}\right)^{a} \cdot\left(C_{c u}\right)^{b} \cdot(S S)^{c} \exp \left(\frac{-E_{a}}{R T}\right) \cdot t \\
& -\ln (1-x)=k_{0}\left(C_{A}\right)^{a} \cdot\left(C_{c u}\right)^{d} \cdot(S S)^{c} \exp \left(\frac{-E_{a}}{R T}\right) \cdot t
\end{aligned}
$$

In Eqs. (12a) and (12b), the values of constants $a$, $b, c$ and $d$ were found to be $0.19,0.51,0.94$, and -0.30 , respectively. The activation energy of dissolution process was calculated from the Arrhenius equation. The activation energy and the pre-exponential factor were calculated to be $31.1 \mathrm{~kJ} / \mathrm{mol}$ and $786.6 \mathrm{~s}^{-1}$, respectively. The value of the activation energy indicates that the rate of dissolution process is controlled by the diffusion [25]. As a result, the kinetic expressions including the reaction parameters used in this dissolution process can be written as in Eqs. (13a) and (13b).

$$
\begin{aligned}
& -\ln (1-x)=786.6\left(C_{A}\right)^{0.19} \cdot\left(C_{c u}\right)^{0.51} \cdot(S S)^{0.94} \exp \left(\frac{-31.1}{R T}\right) \cdot t(13 \mathrm{a}) \\
& -\ln (1-x)=786.6\left(C_{A}\right)^{0.19} \cdot\left(C_{c u}\right)^{-0.30} \cdot(S S)^{0.94} \exp \left(\frac{-31.1}{R T}\right) \cdot t(13 \mathrm{~b})
\end{aligned}
$$

\section{Conclusions}

In this study, the dissolution kinetics of cement copper in aqueous sulfuric acid solutions containing cupric ions was investigated. The effects of the concentration of sulfuric acid, concentration of cupric ion, stirring speed, and reaction temperature on the dissolution behavior of cement copper were determined. It was found that the dissolution rate increased with increasing the acid concentration, stirring speed, and reaction temperature. It was determined that cupric ions have an important effect on the dissolution rate of copper powder. It was observed that the dissolution rate of cement copper increased with increasing the cupric ion concentration up to $0.025 \mathrm{M}$. After this concentration value, it was found that the dissolution rate decreased somewhat with increasing the cupric ion concentration. Copper powder was completely dissolved in sulfuric acid solutions including cupric ions depending on the experimental conditions and reaction time. In light of experimental findings, it can be said that the cupric ion concentration and temperature have more appreciable effects on the dissolution of cement copper powder. Under experimental conditions of a sulfuric acid concentration of $1 \mathrm{M}$, a cupric ion concentration of $0.025 \mathrm{M}$, a reaction temperature of $353 \mathrm{~K}$, and a stirring speed of $500 \mathrm{rpm}$, it was determined that $98 \%$ of the copper powder was dissolved after $180 \mathrm{~min}$ of reaction time. It was found that the reaction rate fits the first order pseudo-homogenous kinetic model. The activation energy of the dissolution process was calculated to be $31.1 \mathrm{~kJ} / \mathrm{mol}$. After cement copper is dissolved in acidic solution, a high-purity metallic copper can be produced by 
electrolysis as well as various copper compounds can be also produced by applying the evaporative crystallization and chemical precipitation processes.

\section{References}

[1] Venkatachalam S.: Hydrometallurgy. Narosa Publishing House, Delhi, India 1998.

[2] Noubactep C.: J. Hazard. Mater., 2010, 81, 1170.

https://doi.org/10.1016/j.jhazmat.2010.05.085

[3] Demirkıran N.: Rev. Chim., 2013, 64, 378.

[4] Shishkin A., Mironovs V., Vu H. et al.: Metals, 2018, 8, 920.

https://doi.org/10.3390/met8110920

[5] Habashi F.: Handbook of Extractive Metallurgy. Wiley, New York 1997.

[6] Karavasteva M.: Hydrometallurgy, 2005, 76, 149. https://doi.org/10.1016/j.hydromet.2004.10.003

[7] Gana R., Figueroa M., Sanchez J.M., Esteso M.: J. Appl.

Electrochem., 1995, 25, 240. https://doi.org/10.1007/BF00262962

[8] Figueroa M., Gana R., Kattan L. et al.: J. Appl. Electrochem., 1997, 27, 99. https://doi.org/10.1023/A:10264792

[9] Ekmekyapar A., Demirkıran N., Künkül A. et al.: Braz. J. Chem. Eng., 2015, 32, 155. https://doi.org/10.1590/0104-

6632.20150321s00003211

[10] Tanaydın M., Demirkıran N.: Sep. Sci. Technol., 2019, 54, 815. https://doi.org/10.1080/01496395.2018.1512619

[11] Demirkıran N.: Ind. Eng. Chem. Res., 2013, 52, 8157. https://doi.org/10.1021/ie400438b

[12] Wong D., Coller B., Macfarlane D.: Electrochim. Acta, 1993, 38, 2121. https://doi.org/10.1016/0013-4686(93)80350-9

[13] Grishina E., Udalova A., Rumyantsev E.: Russ. J. Electrochem., 2002, 38, 155. https://doi.org/10.1016/00134686(93)80350-9

[14] Sribnyi V., Kuntyi O., Yavors'kyi V.: Mater. Sci., 2001, 37, 524. https://doi.org/10.1023/A:10132266

[15] Sameh S., Salih I., Alwash S., Al-Waisty A.: Eng. Technol. J., 2009, 27, 993.

[16] Baeshov A., Kadirbayua A., Jurinov M.: Int. J. Chem. Sci., 2014, 12, 1009.
[17] Park I., Yoo K., Alorro R. et al.: Mater. Trans., 2017, 58, 1500. https://doi.org/10.2320/matertrans.M2017147

[18] Khalid M., Hamuyuni J., Agarwal V. et al.: J. Clean. Prod., 2019, 215, 1005. https://doi.org/10.1016/j.jclepro.2019.01.083

[19] Castillo J., Sepúlveda R., Araya G. et al.: Minerals, 2019, 9, 319. https://doi.org/10.3390/min9050319

[20] Koyama K., Tanaka M., Lee J.: Mater.Trans., 2006, 47, 1788. https://doi.org/10.2320/matertrans.47.1788

[21] Read A.: J. Phys. Chem., 1972, 76, 3656.

https://doi.org/10.1021/j100668a026

[22] Wen C.: Ind. Eng. Chem., 1968, 60, 34.

https://doi.org/10.1021/ie50705a007

[23] Levenspiel O.: Chemical Reaction Engineering. John Wiley, New York 1972.

[24] Mazet N.: Int. Chem. Eng., 1992, 32, 271.

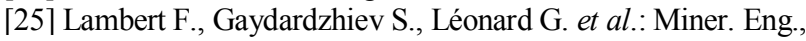
2015, 76, 38. https://doi.org/10.1016/j.mineng.2014.12.029

Received: August 20, 2019 / Revised: October 08, 2019/

Accepted: February 12, 2020

\section{КІНЕТИЧНА МОДЕЛЬ РОЗЧИНЕННЯ ЦЕМЕНТАЦІЙНОЇ МІДІ В РОЗЧИНАХ СУЛЬФАТНОЇ КИСЛОТИ, ЩО МІСТЯТЬ ЙОНИ МІДІ}

Анотація. Досліджено кінетику розчинення порошку иементаційної міді в розчинах сульфатної кислоти, щчо містять йони міді. Визначено, що швидкість розчинення міді підвищується зі збільшенням концентрації кислоти, температури та швидкості перемішування. Встановлено, щзо швидкість розчинення посилюється зі збільшенням концентрації йонів міді до 0,025 М. Температура та концентрація йонів міді мають більш значний вплив на розчинення мідного порошку. Проведено кінетичний аналіз процесу, $і$ встановлено, щзо він відповідає псевдо-гомогенній моделі реакиій першого порядку. Розрахована енергія активачії становила 31,1 кДж/моль.

Ключові слова: малахіт, цементаційна мідь, йони міді, розчинення, кінетика. 